\title{
Multiple Antibiotic Resistance in Planktonic Luminous Bacteria of Indian Penaeid Shrimp Farms
}

\author{
T. J. Abraham* and D. Sasmal \\ Department of Aquatic Animal Health, Faculty of Fishery Sciences, West Bengal University of \\ Animal and Fishery Sciences, 5 - Budherhat Road, Chakgaria, P.O. Panchasayar, Kolkata-700 094, \\ West Bengal, India
}

Received 16 June 2013, accepted in final revised form 13 November 2013

\begin{abstract}
Prevalence of luminous bacteria (LB) in grow-out pond water and sediment samples, and antibiotic resistance among planktonic LB of two major shrimp farming States of India namely Tamil Nadu and West Bengal were studied. Luminous bacterial counts in the range of $\log 0.70-3.64 / \mathrm{mL}$ pond water and $\log 2.00-4.90 / \mathrm{g}$ pond sediment were recorded. The Tamil Nadu shrimp pond water recorded five planktonic luminous bacterial species, viz. Vibrio fischeri, V. harveyi, V. orientalis, V. splendidus biotype1 and Photobacterium leiognathi; while the West Bengal shrimp pond water had only two species $-V$. harveyi and $V$. splendidus biotype 1. Vibrio harveyi was the most dominant species in both cases, constituting about $90-97 \%$ of the total planktonic LB. Majority of the LB isolates from Tamil Nadu shrimp farms were resistant to ciprofloxacin, gentamycin, nitrofurantoin and oxytetracycline; while the West Bengal strains were resistant to co-trimoxazole and oxytetracycline. None of the 420 planktonic LB was resistant to chloramphenicol. The planktonic $V$. harveyi recorded minimal inhibitory concentrations $\geq 100 \mu \mathrm{g} / \mathrm{mL}$ for gentamycin, nitrofurantoin, oxytetracycline and co-trimoxazole. Multiple antibiotic resistance was significantly high $(P<0.01)$ in planktonic LB of Tamil Nadu $(67 \%)$ compared to West Bengal (44\%).
\end{abstract}

Keywords: Shrimp farming; Multiple antibiotic resistance; Vibrio fischeri; V. harveyi; V. orientalis; $V$. splendidus biotype1.

(C) 2014 JSR Publications. ISSN: 2070-0237 (Print); 2070-0245 (Online). All rights reserved.

doi: http://dx.doi.org/10.3329/jsr.v6i1.15329 J. Sci. Res. 6 (1), 153-159 (2014)

\section{Introduction}

Shrimp farming has encountered with disease problems similar to other sectors of intensive husbandry. The growing use of antibiotics to combat the problem of bacterial diseases in shrimp aquaculture has led to concern about effects of their release into

\footnotetext{
*Corresponding author: abrahamtj1@gmail.com
} 
adjacent coastal environments and also the possible development of antibiotic-resistance in aquatic bacteria. Antibiotic resistance as a phenomenon is newly worrying because it is accumulating and accelerating, while the world's tools for combating it decrease in power and number. Research in this area has mainly focused on fish pathogens. Similar studies on normal bacterial flora of aquatic ecosystem are given much importance in recent years $[1,2]$. Luminous bacteria (LB) are ubiquitous and ecologically versatile group, found saprophytically and parasitically on marine animals and live symbiotically in specialized organs of fish or in enteric tracts of fish and shrimp [3]. These organisms have been employed in coastal pollution surveillance, toxicity and water quality testing [4-6]. The purpose of this investigation was to determine the level of antibiotic-resistance in planktonic LB of Indian shrimp farms in which the external stress is present.

\section{Experimental}

\subsection{Materials and methods}

Samples of grow-out pond sediment, pond water and source water from shrimp culture systems were collected along the coastal belt of Tamil Nadu and West Bengal, India between 1994 and 2008 for quantitative studies on LB and the details of which are described in Abraham et al. [6, 7]. Luminous bacterial counts (LBC) and total viable counts (TVC) were enumerated by spread plating on seawater complex (SWC) agar [8] and tryptic soy agar (HiMedia, India) supplemented with $1 \%$ (w/v) $\mathrm{NaCl}$ (TSA), respectively. Briefly, the sediment samples, taken at four places from each pond, were pooled together and mixed thoroughly in a homogenizer before analyses. Surface water samples were collected in $300 \mathrm{~mL}$ capacity sterilized containers. Ten-fold serial dilutions of water and sediment samples were prepared and appropriate dilutions of the samples were plated on to TSA and SWC agar. All plates were incubated at $30 \pm 2{ }^{\circ} \mathrm{C}$ for $48 \mathrm{~h}$. Luminescence on SWC agar was observed in a dark room after 16-20 h of incubation. Luminous colonies with distinct colony characteristics were aseptically picked, streaked repeatedly on SWC agar until pure and maintained on SWC agar slants. Luminous bacterial isolates were identified as described elsewhere $[6,9,10]$ following the scheme of Abraham et al. [11]. A total of 420 planktonic LB strains comprising 224 from Tamil Nadu and 196 from West Bengal were screened for their antibiotic sensitivity to six broad spectrum antibiotics namely chloramphenicol $(30 \mu \mathrm{g})$ ciprofloxacin $(5 \mu \mathrm{g})$, gentamycin $(10 \mu \mathrm{g})$, nitrofurantoin $(300 \mu \mathrm{g})$, oxytetracycline $(30 \mu \mathrm{g})$ and co-trimoxazole $(25 \mu \mathrm{g})$ following agar-disc diffusion method [12] on Mueller Hinton agar (HiMedia, India) supplemented with $1 \%(\mathrm{w} / \mathrm{v}) \mathrm{NaCl}$ (MHA). Minimal inhibitory concentration (MIC) of antibiotics against 85 planktonic Vibrio harveyi isolates was determined by agar dilution method on MHA [13]. Multiple antibiotic resistance (MAR) was derived from the antibiogram data. The results of the bacterial counts were processed by log transformation and the significance of differences were tested by Student ' $t$ ' test. Chi square test was followed to determine the significance of difference in MAR [14]. 


\section{Results and Discussion}

The results of the bacterial counts of shrimp grow-out pond water, pond sediment and source water are presented in Figs. 1 and 2. Presence of LB in high numbers in coastal waters was correlated with healthy and pollution free condition and, hence, these group of bacteria are proposed as useful biomarkers in the assessment of environmental health [4]. The present study, therefore, assessed the impact of shrimp aquaculture activities particularly the use of aquadrugs on the development of antibiotic resistance in planktonic LB, which are ubiquitous in marine environment and ecologically versatile [3]. The results on the counts of LB from penaeid shrimp pond water and sediment samples of Tamil Nadu and West Bengal, as depicted in Fig. 1, evidently showed that LB are the normal inhabitants of shrimp farming systems. Significant differences existed among the TVCs of pond water and source water samples of Tamil Nadu and West Bengal shrimp farms $(\mathrm{P}<0.05)$. The West Bengal farms recorded high TVCs and the magnitude of increase was to the tune of $1.80 \mathrm{log}$ units in pond water and $1.40 \log$ units in source water. The TVCs of pond sediment, however, differed insignificantly $(\mathrm{P}>0.05)$. Likewise, significant differences in LBCs were recorded among the pond sediment and source water samples $(P<0.05)$. The pond water LBCs, however, differed insignificantly $(\mathrm{P}>0.05)$. The source water of Tamil Nadu shrimp farms recorded high proportion of planktonic LB $(3.11 \pm 1.17 \%)$ than that of West Bengal $(0.55 \pm 0.53 \%)$. The pond sediment samples of Tamil Nadu recorded high LBCs; while the pond water samples of West Bengal had high LBCs. The results of quantitative bacteriology (Figs. 1 and 2) revealed luminous bacterial abundance in the West Bengal shrimp farm environment, possibly due to nutrient enrichment or cluster of shrimp aquaculture activities. Nevertheless, the proportion of LB was higher in Tamil Nadu shrimp farm samples than in West Bengal. The study by Abraham et al. [6] in Tamil Nadu revealed that the shrimp farming activities, which largely contributed to LB population, strongly influence the distribution of planktonic LB in the coastal waters.

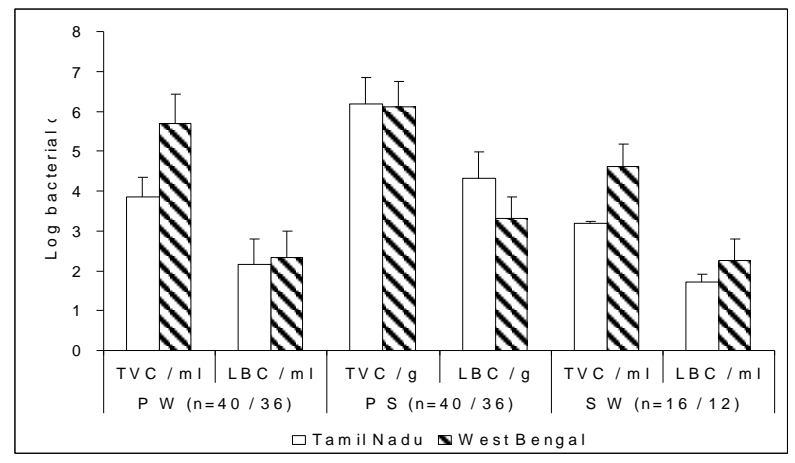

Fig. 1. Total viable counts (TVC) and luminous bacterial counts (LBC) in pond water (PW), pond sediment (PS) and source water (SW). 


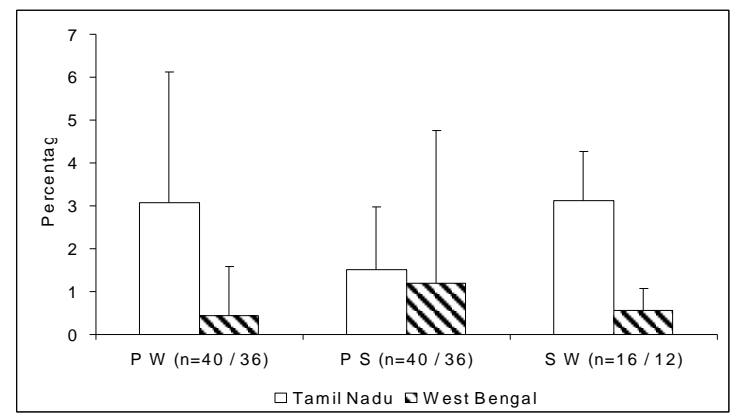

Fig. 2. Proportion of luminous bacteria in pond water (PW), pond sediment (PS) and source water (SW).

Five luminous bacterial species, viz., Vibrio fischeri, $V$. harveyi, V. orientalis, $V$. splendidus biotype1 and Photobacterium leiognathi were identified from the shrimp grow-out pond water samples of Tamil Nadu. West Bengal shrimp pond water harboured only $V$. harveyi, and $V$. splendidus biotype1. Vibrio harveyi was the dominant flora in all the samples, constituting about $90-97 \%$ of the total planktonic LB population (Table 1). The ecology of LB in Indian shrimp farming systems was described in our earlier reports $[6,7,15]$. Vibrio fischeri is reportedly highly sensitive to a variety of chemicals and used in ecotoxicologic monitoring and toxicity testing [5]. The absence of certain luminous species, particularly $V$. fischeri in West Bengal shrimp pond water probably indicated unfaourable environmental conditions for these luminous species or the presence of $V$. fischeri inhibitory agents in pond water. The results are, more or less, in agreement with the observations of Ramaiah and Chandramohan [4], who reported absence of LB in the water samples of Hoogly estuary (off Haldia) in West Bengal.

Table 1. Multiple antibiotic resistance (MAR)* in planktonic LB of shrimp farms of Tamil Nadu and West Bengal, India.

\begin{tabular}{|c|c|c|c|c|}
\hline \multirow{2}{*}{$\begin{array}{l}\text { Planktonic luminous } \\
\text { species }\end{array}$} & \multicolumn{2}{|c|}{ Prevalence $(\%)$} & \multicolumn{2}{|l|}{$\operatorname{MAR}(\%)$} \\
\hline & $\begin{array}{l}\text { Tamil Nadu } \\
(\mathrm{N}=224)\end{array}$ & $\begin{array}{l}\text { West Bengal } \\
(\mathrm{N}=196)\end{array}$ & $\begin{array}{l}\text { Tamil Nadu } \\
(\mathrm{N}=224)\end{array}$ & $\begin{array}{l}\text { West Bengal } \\
(\mathrm{N}=196)\end{array}$ \\
\hline $\begin{array}{l}\text { Photobacterium } \\
\text { leiognathi }\end{array}$ & 1.79 & 0 & $25.00^{\mathrm{a}, \mathrm{b}, \mathrm{c}}$ & - \\
\hline Vibrio fischeri & 2.23 & 0 & 0 & - \\
\hline V. harveyi & 90.18 & 96.94 & $75.74^{\mathrm{a}, \mathrm{d}, \mathrm{e}, 1}$ & $48.95^{\mathrm{a}, 1}$ \\
\hline V. orientalis & 3.12 & 0 & $57.14^{\mathrm{b}, \mathrm{d}}$ & - \\
\hline $\begin{array}{l}\text { V. splendidus } \\
\text { biotype1 }\end{array}$ & 2.68 & 3.06 & $50.00^{\mathrm{ce}, 2}$ & $33.33^{\mathrm{a}, 2}$ \\
\hline
\end{tabular}

${ }^{*}$ MAR $=$ Resistant to at least two antibiotics. a-e: Values sharing common superscripts within the column differed significantly $(P<0.01)$. 1-2: Values sharing common superscripts within the rows differed significantly $(P<0.05)$. 
As seen in Fig. 3, all the planktonic LB isolates from Tamil Nadu and West Bengal $(n=420)$ were sensitive to chloramphenicol, one of the antibiotics banned for aquaculture use in India. Majority of the planktonic LB isolates from Tamil Nadu shrimp farms were resistant to ciprofloxacin (72\%), nitrofurantoin (51\%), gentamycin (46\%) and oxytetracycline (40\%); while the West Bengal isolates were resistant to co-trimoxazole $(59 \%)$ and oxytetracycline $(40 \%)$. The incidence of MAR was more in Tamil Nadu (66.96\%) compared to West Bengal (43.88\%) planktonic LB isolates. None of the isolate was resistant to all six antibiotics and about 89 isolates were sensitive to all the antibiotics tested (Fig. 4). The observations on high incidence of resistance to other banned antibiotics such as ciprofloxacin, nitrofurantoin and gentamycin, and also to cotrimoxazole and oxytetracycline in planktonic LB isolates probably indicated abuse of these antibiotics in shrimp aquaculture. The results corroborate the observations of Tendencia and de la Pena [16]. The MAR was high in $V$. harveyi followed by $V$. orientalis and $V$. splendidus biotype 1 (Table 1 ). The minimal inhibitory concentration (MIC) values of ciprofloxacin $(0.10-1.56 \mu \mathrm{g} / \mathrm{mL})$ and chloramphenicol $(0.20-6.25 \mu \mathrm{g} / \mathrm{mL})$ were the lowest; while the MICs of gentamycin, nitrofurantoin, oxytetracycline and co-trimoxazole were up to $100 \mu \mathrm{g} / \mathrm{mL}$ or above against planktonic luminous $V$. harveyi (Table 2). The development of MAR is of great concern to shrimp aquaculture. As shown in Fig. 4, the MAR was significantly high $(P<0.05)$ in Tamil Nadu than in West Bengal LB isolates. There existed significant differences in MAR among the luminous species and between the luminous species of Tamil Nadu and West Bengal. The MAR was significantly high in $V$. harveyi $(P<0.01)$ and antibiotic resistant $V$. harveyi was reportedly virulent to shrimp larvae $[17,18]$. The high minimal inhibitory concentrations $(\geq 100 \mu \mathrm{g} / \mathrm{ml})$ recorded for certain antibiotics against planktonic luminous $V$. harveyi is a serious cause for concern. The high MICs obtained would mean high concentrations have to be used to eliminate them or other bacterial pathogens in situ. The prohibitive cost of antibiotic treatment would be particularly disadvantageous and their use would not be economically feasible even if all isolates were found to be susceptible. Anderson and Levin [19] opined that the frequency and rates of ascent and dissemination of antibiotic resistance in bacterial populations are directly related to the volume of antibiotic used. The fact is that farmers of both States used different types of aqua drugs during various stages of shrimp production $[15,20]$.

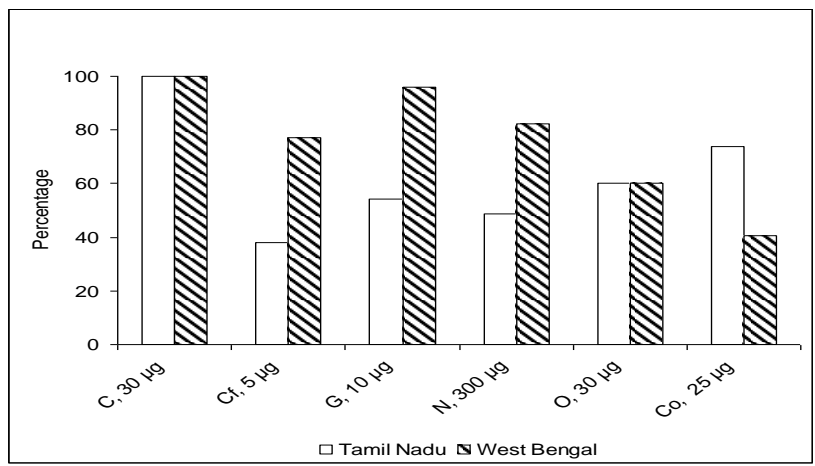

Fig. 3. Sensitivity of planktonic luminous bacteria to chloramphenicol (C), ciprofloxacin (Cf), gentamycin $(\mathrm{G})$, nitrofurantoin $(\mathrm{N})$, oxytetracycline $(\mathrm{O})$ and co-trimoxazole $(\mathrm{Co})$. 
Table 2. Ranges of minimum inhibitory concentration (MIC) of antibiotics against planktonic Vibrio harveyi from shrimp farms of Tamil Nadu and West Bengal, India.

\begin{tabular}{lll}
\hline Antibiotic & MIC $(\mu \mathrm{g} / \mathrm{mL})$ & \\
\cline { 2 - 3 } & Tamil Nadu $(n=45)$ & West Bengal $(n=40)$ \\
\hline Chloramphenicol & $0.78-6.25$ & $0.20-6.25$ \\
Ciprofloxacin & $0.20-1.56$ & $0.10-0.78$ \\
Gentamycin & $1.56-50.00$ & $6.25->100.00$ \\
Nitrofurantoin & $6.25->100.00$ & $6.25-12.50$ \\
Oxytetracycline & $0.78-6.25$ & $6.25->100.00$ \\
Co-trimoxazole & $0.20-50.00$ & $1.56-200.00$ \\
\hline
\end{tabular}

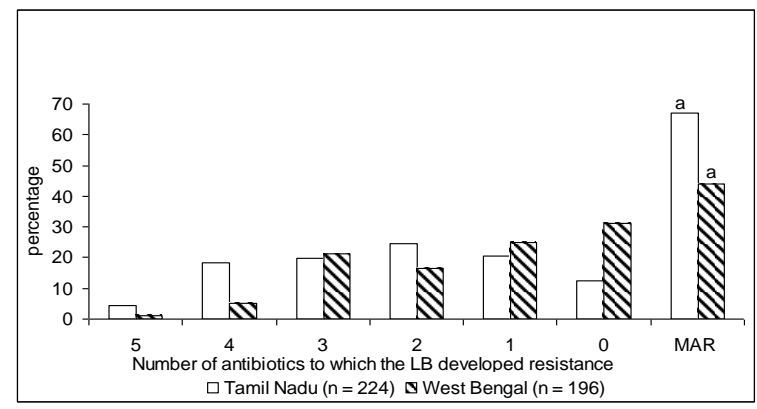

Fig. 4. Multiple antibiotic resistance (MAR) in planktonic luminous bacteria (LB) of shrimp farms. MAR = Resistant to at least two antibiotics, a: The bars sharing common alphabet differed significantly $(P<0.01)$.

\section{Conclusion}

As majority of the Indian shrimp farms have free exchange of water with sea, these MAR bacteria may spread with water circulation and pose problems to shrimp culture activities in the surrounding area and public health. It is worthy to mention here that within the study period majority of the shrimp farmers in Thoothukudi district, Tamil Nadu, wherein sampling was done, discontinued the shrimp culture in the late 1990s, so also Midnapore (East) district, West Bengal in the early 2000s due to repeated outbreak of diseases, probably a consequence of imbalance in autochthonous microflora [6] and increased prevalence of multiple antibiotic resistant bacteria as confirmed in this study.

\section{References}

1. H. P. Serrano, Responsible Use of Antibiotics in Aquaculture, FAO Fisheries Technical Paper. No. 469 (FAO, Rome, 2005) p. 97. 
2. FAO/OIE/WHO, Report of a Joint FAO/OIE/WHO Expert Consultation on Antimicrobial Use in Aquaculture and Antimicrobial Resistance. Seoul, Republic of Korea, 13-16 June 2006. Department of Food Safety, Zoonoses and Foodborne Diseases (World Health Organization, Geneva, Switzerland, 2006) p. 97.

3. K. H. Nealson and J.W. Hastings, The Luminous Bacteria. In: The Prokaryotes, $2^{\text {nd }}$ edition, Vol. 1, Ed. A. Balows, H. G. Trueper, M. Dworkin, W. Harder and K. H. Schleifer (SpringVerlag, New York, 1991) pp. 625-639.

4. N. Ramaiah and D. Chandramohan, Mar. Pollut. Bull. 26, 190 (1993). http://dx.doi.org/10.1016/0025-326X(93)90621-P

5. K. L. E. Kaiser, Environ. Health Perspect. 106, 583 (1998).

6. T. J. Abraham, S. A. Shanmugam, R. Palaniappan, and K. Dhevendaran, Indian J. Mar. Sci. 32 (3), 208 (2003).

7. T. J. Abraham, T. Sengupta, and D. Sasmal, Indian J. Fish. 54 (1), 37 (2007).

8. E. G. Ruby and J.G. Morin, Appl. Environ. Microbiol. 38, 406 (1979).

9. P. Baumann, A. L. Furniss, and J. V. Lee, Genus I. Vibrio Pacini 1854. In: Bergey's Manual of Systematic Bacteriology, Vol. 1. Ed. N. R. Krieg, and J. G. Holt (Williams and Wilkins, Baltimore, MD, 1984) pp. 518-538.

10. T. J. Abraham, S. A. Shanmugam, K. Dhevendran, and R. Palaniappan, Indian J. Fish. 55 (4), 311 (2008).

11. T. J. Abraham, R. Palaniappan, and K. Dhevendaran, Indian J. Mar. Sci. 28, 35 (1999).

12. A. W. Bauer, W. M. M. Kirby, J. C. Sherris, and M. Turck, Am. J. Clin. Pathol. 45, 493 (1966).

13. L. L. Mohney, T. A. Bell, and D. V. Lightner, J. Aquat. Ani. Health 4, 257 (1992). http://dx.doi.org/10.1577/1548-8667(1992)004<0257:SATIIV>2.3.CO;2

14. G. W. Snedecor and W. C. Cochran, Statistical Methods (Oxford and IBH Publishing Co., Calcutta, India, 1967) p. 593.

15. T. J. Abraham and R. Palaniappan, Aquaculture 232, 81 (2004).

16. E. A. Tendencia and L. D. de la Pena, Aquaculture 195, 193 (2001). http://dx.doi.org/10.1016/S0044-8486(00)00570-6

17. I. Karunasagar, R. Pai, G. R. Malathi, and I. Karunasagar, Aquaculture 128, 203 (1994).

18. T. J. Abraham, Indian J. Mar. Sci. 35 (3), 275 (2006).

19. D. I. Anderson and B. R. Levin, Curr. Opin. Microbiol. 2, 489 (1999). http://dx.doi.org/10.1016/S1369-5274(99)00005-3

20. T. J. Abraham and D. Sasmal, J. Inland. Fish. Soc. India 37 (2), 26 (2005). 